\title{
A straightforward conversion of 1,4-quinones into polycyclic pyrazoles via [3+2]-cycloaddition with fluorinated nitrile imines
}

\author{
Greta Utecht-Jarzyńska ${ }^{1}$, Karolina Nagła ${ }^{1}$, Grzegorz Mlostoń ${ }^{1}$, Heinz Heimgartner², \\ Marcin Palusiak ${ }^{3}$ and Marcin Jasiński ${ }^{*}$
}

Open Access

\author{
Full Research Paper \\ Address: \\ ${ }^{1}$ Department of Organic and Applied Chemistry, Faculty of Chemistry, \\ University of Lodz, Tamka 12, 91403 Łódź, Poland, ${ }^{2}$ Department of \\ Chemistry, University of Zurich, Winterthurerstrasse 190, CH-8057 \\ Zurich, Switzerland and ${ }^{3}$ Department of Physical Chemistry, Faculty \\ of Chemistry, University of Lodz, Pomorska 163/165, 90236 Łódź, \\ Poland \\ Email: \\ Marcin Jasiński - mjasinski@uni.lodz.pl \\ * Corresponding autho \\ Keywords: \\ $[3+2]$-cycloadditions; fluorinated compounds; fused pyrazoles; \\ $\mathrm{N}$-heterocycles; nitrile imines; 1,4-quinones
}

Beilstein J. Org. Chem. 2021, 17, 1509-1517.

https://doi.org/10.3762/bjoc.17.108

Received: 26 April 2021

Accepted: 17 June 2021

Published: 28 June 2021

This article is dedicated to Professor Dieter Lentz (Berlin) on the occasion of his 70th birthday.

Associate Editor: I. Baxendale

(C) 2021 Utecht-Jarzyńska et al.; licensee Beilstein-Institut.

License and terms: see end of document.

\begin{abstract}
In-situ-generated $N$-aryl nitrile imines derived from trifluoroacetonitrile efficiently react with polycyclic 1,4-quinones, yielding fused pyrazole derivatives as the exclusive products. The reactions proceed via the initially formed [3+2]-cycloadducts, which undergo spontaneous aerial oxidation to give aromatized heterocyclic products. Only for 2,3,5,6-tetramethyl-1,4-benzoquinone, the expected [3+2]-cycloadduct exhibited fair stability and could be isolated in moderate yield $(53 \%)$. The presented method offers a straightforward access to hitherto little known trifluoromethylated polycyclic pyrazoles. All products were isolated as pale colored solids with medium-intensity absorption maxima in the range of 310-340 nm for naphthoquinone-derived products and low-intensity bands in the visible region $(\approx 400 \mathrm{~nm})$ for the anthraquinone series.
\end{abstract}

\section{Introduction}

The 1,4-quinone scaffold belongs to the most important structural motifs present in naturally occurring compounds as well as synthetic drugs and other functionalized organic molecules of great practical importance, e.g., in materials chemistry (Figure 1) [1-4].
Selective functionalization of 1,4-quinones is a challenging task in current organic synthesis, and diverse transformations are known to create new $\mathrm{C}-\mathrm{C}$ bonds and/or to extend the (poly)cyclic system. In this context, cycloadditions are of special importance, and Diels-Alder reactions have successful- 
<smiles>O=C1C(O)=C(C2CCC(c3ccc(Cl)cc3)CC2)C(=O)c2ccccc21</smiles>

atovaquone (antimalarial)<smiles>Cn1c(/C=C/CO)c(CO)c2c1C(=O)C=C(N1CC1)C2=O</smiles>

apaziquone (chemotherapeutic prodrug)<smiles>Cc1c(C(=O)O)c(O)cc2c1C(=O)c1c(O)c([C@H]3O[C@H](CO)[C@@H](O)[C@H](O)[C@H]3O)c(O)c(O)c1C2=O</smiles>

carminic acid (natural red dye)

Figure 1: Structures of exemplary benzo- and heteroaromatic fused 1,4-quinone drugs and natural products.

ly been explored in conversions aimed at the construction of a new, six-membered ring [5]. However, [3 + 2]-cycloadditions leading to five-membered heterocycles are less often employed in spite of the high dipolarophilicity of the $\alpha, \beta$-unsaturated diketone system [6-9]. Notably, in the already reported reactions of propargylic 1,3-dipoles, such as nitrile oxides or nitrile ylides, with 1,4-quinones, competitive reaction courses involving either ethylenic $\mathrm{C}=\mathrm{C}$ or carbonyl $\mathrm{C}=\mathrm{O}$ bonds were observed. For example, the more polar arylnitrile oxides and 1,4benzoquinones reacted via addition to the $\mathrm{C}=\mathrm{C}$ bond to give fused isoxazole derivatives [10-12] as well as with the $\mathrm{C}=\mathrm{O}$ bond yielding spirocyclic 1,4,2-dioxazole derivatives [13,14]. Furthermore, for photochemically generated benzonitrile isopropanide, competitive $\mathrm{C}=\mathrm{O}$ and $\mathrm{C}=\mathrm{C}$ additions with 1 ,4quinones were observed [15]. On the other hand, the slightly less polar benzonitrile benzylide underwent $[3+2]$-cycloaddition to the $\mathrm{C}=\mathrm{C}$ bond exclusively [16]. Noteworthy, $[3+2]$-cycloadditions of nitrile imines to the $\mathrm{C}=\mathrm{O}$ group of $1,4-$ quinones have not yet been reported.

In a historical work by Rolf Huisgen et al., the first [3 + 2]-cycloadditions of some 1,4-quinones, e.g., 1,4-naphthoquinone (1a), with $C, N$-diphenyl nitrile imine (2) were reported in the 1960s [17]. The latter 1,3-dipole was generated thermally from the respective tetrazole derivative $\mathbf{3}$, and the observed $[3+2]$-cycloadditions occurred chemoselectively to provide fused pyrazoles of the type $\mathbf{4}$ as exclusive products (Scheme 1).

This type of cycloaddition attracted considerable attention of other groups $[18,19]$ and recently has been applied for the prep-

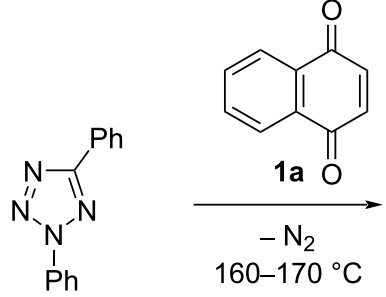

3<smiles>O=C1c2ccccc2C(=O)c2c1nn(-c1ccccc1)c2-c1ccccc1</smiles>

$4(85 \%)$

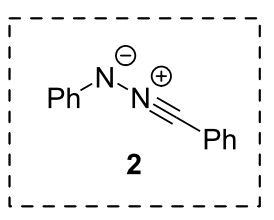

intermediate $\mathrm{C}, \mathrm{N}$-diphenyl nitrile imine

Scheme 1: First [3 + 2]-cycloaddition of 1,4-naphthoquinone (1a) with intermediate nitrile imine 2, generated from tetrazole 3, reported by Huisgen et al. [17]. 
aration of some $\pi$-extended pyrazole derivatives, which exhibited promising biological activity [20].

In a series of our recent publications, efficient syntheses of fluoromethylated five- and six-membered N,S-heterocycles, such as 5 and 6, available via [3 +2$]$-cycloadditions [21-25] or [3 + 3]-annulations [26] of trifluoroacetonitrile imines 7, respectively, were reported (Scheme 2).

Noteworthy, the latter 1,3-dipoles are easily generated under mild conditions via base-mediated dehydrobromination of the respective hydrazonoyl bromides $\mathbf{8}$ and smoothly undergo $[3+2]$-cycloadditions with both electron-rich $\mathrm{C}=\mathrm{C}$ dipolarophiles [27-29] and arynes [30], yielding the corresponding pyrazole derivatives. Unexpectedly, they reacted also with electron-deficient polyfluorinated thioamides to give the desired 1,3,4-thiadiazoles as the products of [3+2]-cycloaddition to the $\mathrm{C}=\mathrm{S}$ bond [25].

Taking into account that fluorinated heterocycles [31-34], including pyrazoles $[31,35,36]$, are of great significance for various medicinal and agricultural applications, the development of new methods for the construction of fluorine-containing organic molecules combined with the 1,4-quinone moiety can be considered as a challenging problem of current organic synthesis. Thus, the main goal of the present study was to check the course of $[3+2]$-cycloaddition reactions of electron-deficient $\mathrm{CF}_{3}$-substituted nitrile imines 7 with 1,4-naphthoquinone (1a) and 1,4-anthraquinone (1b), which were selected as model dipolarophiles. In addition, an important issue of the work was the examination of the chemoselectivity governing the formation of five-membered rings via competitive cycloaddition of the in-situ-generated 1,3-dipoles either onto the $\mathrm{C}=\mathrm{C}$ or $\mathrm{C}=\mathrm{O}$ bond. The present work should also be considered as an extension of our earlier studies focused on the exploration of 1,4- quinones in the $[3+2]$-cycloaddition and hetero-Diels-Alder reaction performed with thiocarbonyl $S$-methanides and thiochalcones, respectively $[37,38]$.

\section{Results and Discussion}

In a preliminary experiment, the reaction of 1,4-naphthoquinone (1a) with $N$-phenyltrifluoroacetohydrazonoyl bromide (8a), used as an easy-to-handle precursor of nitrile imine 7a, was examined. The reaction was performed in selected aprotic organic solvents by using organic and inorganic bases, such as $\mathrm{Et}_{3} \mathrm{~N}, \mathrm{~K}_{2} \mathrm{CO}_{3}$, and DBU. Along with the "traditional" reaction performed in solution, a mechanochemical approach using ball milling was also tested. The obtained results are collected and compared in Table 1. They show that the best results were achieved using dry THF as a solvent and $\mathrm{K}_{2} \mathrm{CO}_{3}$ as a base; under these conditions, the best conversion of the starting materials and the highest yield (93\%) for the expected product 9a were observed. Typically, for cycloadducts obtained from 1,4naphthoquinone [38], the initially formed [3+2]-cycloadduct 10a smoothly underwent air oxidation during the work-up to give pyrazole 9a as the final product.

It is worth mentioning that the solvent-free mechanochemical approach also led to the desired product, albeit a lower yield of 9a was noticed. In these reactions, a sticky material was obtained, which was difficult to grind and therefore, completion of these reactions was practically impossible. On the other hand, the ball mill approach provided the target material after a significantly shorter reaction time ( $3 \mathrm{~h}$ instead of $2 \mathrm{~d}$ ).

Based on the optimized protocol, a series of cycloadditions with nitrile imines 7 was carried out using 1a (Scheme 3). Irrespective of the electronic properties of the substituent $\mathrm{X}$ located at the $\mathrm{C}(4)$ atom of the aryl ring in the precursor $\mathbf{8}$, generally, a high yield of the isolated products 9 was observed (78-97\%).

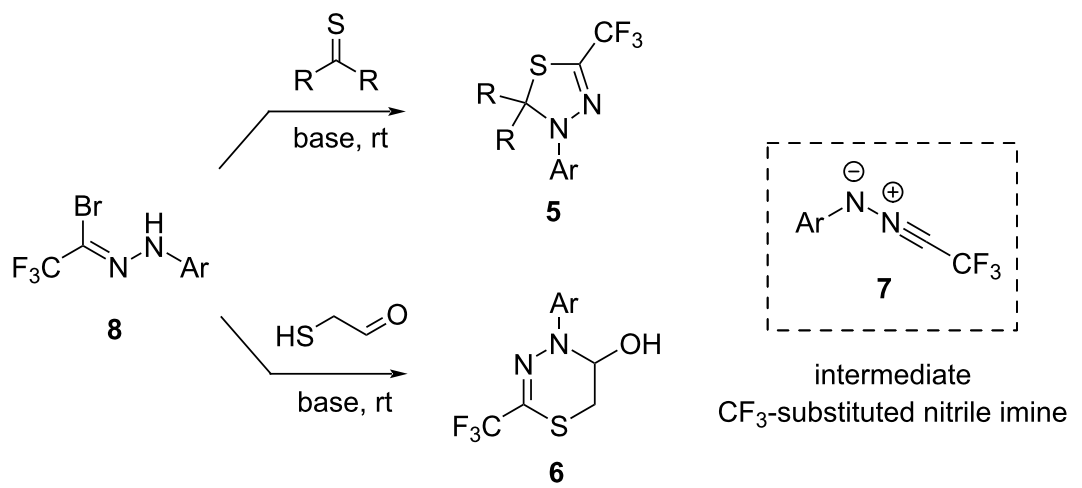

Scheme 2: Selected applications of trifluoroacetonitrile imines 7 in the synthesis of S-containing 5- and 6-membered heterocycles. 
Table 1: Results of the $[3+2]$-cycloaddition of quinone 1a with the fluorinated nitrile imine $7 \mathbf{a}$ generated from $8 \mathbf{a}$.<smiles>O=C1CCC(=O)c2ccccc21</smiles>

1a<smiles>FC(F)(F)C(Br)=NNc1ccccc1</smiles><smiles>O=C1c2ccccc2C(=O)[C@H]2[C@@H]1C(C(F)(F)F)=NN2c1ccccc1</smiles>

$10 a$<smiles>O=C1c2ccccc2C(=O)c2c1c(C(F)(F)F)nn2-c1ccccc1</smiles>

9a

\begin{tabular}{llll}
\hline base & solvent & reaction time & yield (\%) \\
\hline $\mathrm{Et}_{3} \mathrm{~N}$ & $\mathrm{THF}$ & $2 \mathrm{~d}$ & 93 \\
$\mathrm{~K}_{2} \mathrm{CO}_{3}$ & $\mathrm{THF}$ & $2 \mathrm{~d}$ & $97(93)$ \\
$\mathrm{Cs}_{2} \mathrm{CO}_{3}$ & $\mathrm{THF}$ & $2 \mathrm{~d}$ & 90 \\
$\mathrm{DBU}$ & $\mathrm{THF}$ & $2 \mathrm{~d}$ & $-\mathrm{b}$ \\
$\mathrm{K}_{2} \mathrm{CO}_{3}$ & $\mathrm{DCM}$ & $2 \mathrm{~d}$ & 96 \\
$\mathrm{~K}_{2} \mathrm{CO}_{3}$ & toluene & $2 \mathrm{~d}$ & 22 \\
$\mathrm{~K}_{2} \mathrm{CO}_{3}$ & $-\mathrm{c}$ & $3 \mathrm{~h}$ & 85 \\
$\mathrm{Et}_{3} \mathrm{~N}$ & $-\mathrm{c}$ & $3 \mathrm{~h}$ & $79^{\mathrm{d}}$ \\
\hline
\end{tabular}

aConversion of naphthoquinone (1a) into $9 \mathrm{a}$ estimated on the basis of ${ }^{1} \mathrm{H}$ NMR spectra of the crude reaction mixture. Yield of isolated product given in parentheses. byrazole 9 a was not found in the mixture. 'Solvent-free ball mill reaction. dPartial decomposition of the starting bromide 8 a.<smiles>CC(=O)c1cc2ccccc2cc1C(C)=O</smiles>

1a, $n=0$

1b, $n=1$<smiles>[X]c1ccc(NN=C(Br)C(F)(F)F)cc1</smiles>

8a-h<smiles>[X]c1ccc(-n2nc(C(F)(F)F)c3c2C(=O)c2cc4ccccc4cc2C3=O)cc1</smiles>

9a, $X=H(93 \%)$

9b, $X=O B n(78 \%)$

9c, $X=$ OMe $(97 \%)$

9d, $X=\operatorname{Me~}(90 \%)$

9e, $X=\mathrm{PhCO}_{2}$ (89\%)

9f, $\mathrm{X}=\mathrm{Cl}(84 \%)$

9g, $X=\mathrm{CN}(41 \%)$

9h, $X=\mathrm{NO}_{2}(64 \%)$<smiles>[X]c1ccc(-n2nc(C(F)(F)F)c3c2C(=O)c2ccccc2C3=O)cc1</smiles>

9i, $X=O B n(87 \%)$

9j, $X=$ OMe $(74 \%)$

9k, $X=M e(92 \%)$

9l, $\mathrm{X}=\mathrm{Cl}(63 \%)$

Scheme 3: Synthesis of [3+2]-cycloadducts $9 \mathbf{a}-\mathbf{I}$ derived from $\mathrm{CF}_{3}$-substituted nitrile imines $\mathbf{7 a - h}$ and 1,4-quinones $\mathbf{1 a}$ and $\mathbf{1 b}$.

Only for derivatives bearing strongly electron-withdrawing groups $\mathrm{X}$ (i.e., $\mathrm{CN}, \mathrm{NO}_{2}$ ), a longer reaction time (up to $6 \mathrm{~d}$ ) was required to complete these experiments, and the yield of the isolated products dropped significantly (to 41 and $64 \%$, respectively). In analogy to the tricyclic pyrazole derivative 9a, the expected products $\mathbf{9 b}-\mathbf{h}$ formed after spontaneous aromatization of the initial $[3+2]$-cycloadducts by air oxidation were isolated exclusively. Additionally, the X-ray structure of $\mathbf{9 d}$ is shown in Figure 2.

Similar results were obtained starting with 1,4-anthraquinone (1b) and selected hydrazonoyl bromides 8 . In this series, 


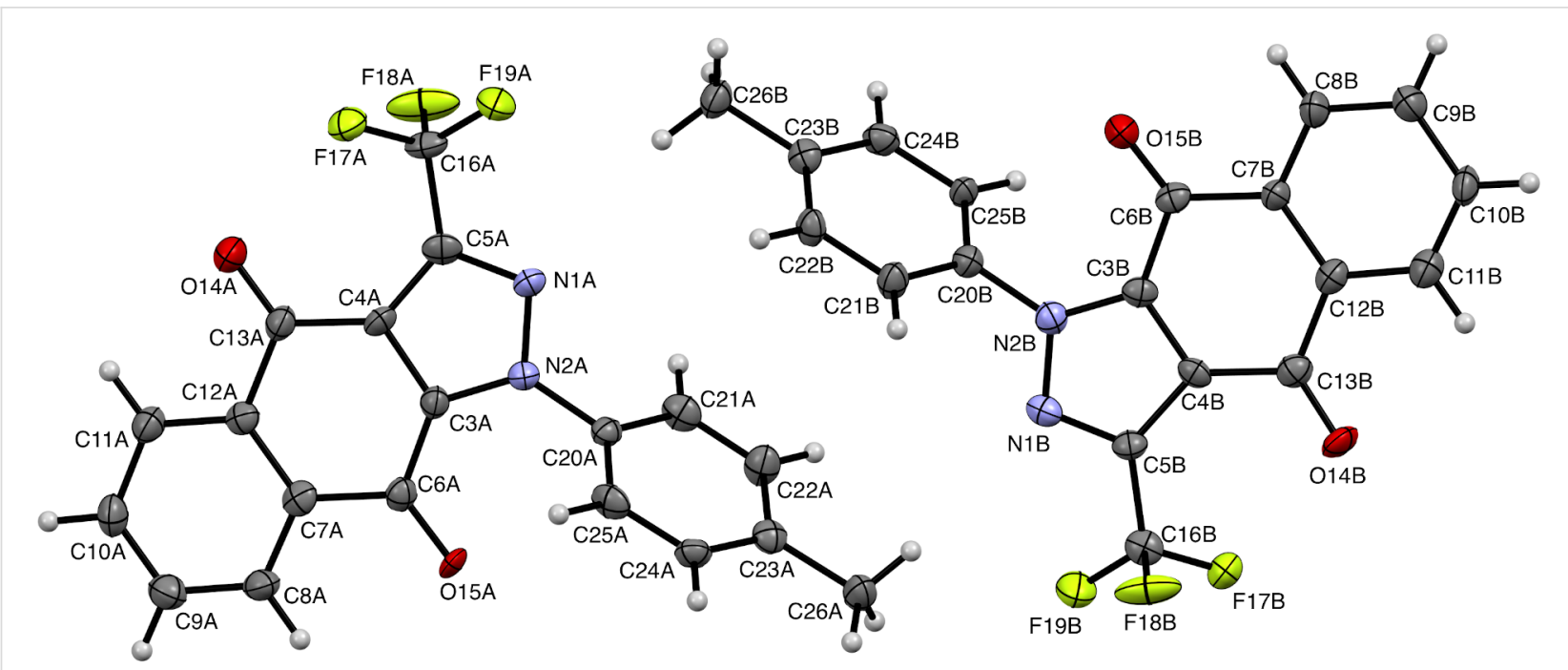

Figure 2: X-ray structure of 3-trifluoromethylpyrazole derivative 9d. The labeling scheme of the asymmetric unit is shown. Anisotropic displacement parameters of nonhydrogen atoms are drawn as ellipsoids with a $50 \%$ probability level. $\mathrm{N}$ atoms in blue, $\mathrm{O}$ atoms in red, $\mathrm{C}$ atoms in grey, $\mathrm{H}$ atoms as small white spheres. Structure deposited under deposition number CCDC-2078498.

fused pyrazoles $\mathbf{9 i}-\mathbf{l}$ were obtained in high yield (63-92\%, Scheme 3).

Finally, the experiment performed under the optimized conditions with the nonsymmetric menadione (1c, vitamin $\mathrm{K}_{3}$ ), bearing the Me group at $\mathrm{C}(2)$, with in-situ-generated nitrile imines 7c $(\mathrm{X}=\mathrm{OMe})$ and $7 \mathbf{d}(\mathrm{X}=\mathrm{Me})$ led to complex mixtures of unidentified products (Scheme 4 ). These results differ from that reported by Huisgen [17], who in the reaction of nitrile imine 2 with the same dipolarophile obtained the expected $[3+2]$-cycloadduct to the $\mathrm{C}=\mathrm{C}$ bond as a single regioisomer, which was isolated in $33 \%$ yield. The observed outcome suggests that the thermally generated nitrile imine $\mathbf{2}$ undergoes $[3+2]$-cycloaddition more efficiently than fluorinated nitrile imines 7 generated under basic conditions. It seems likely that in the presence of a base, sequential reactions of the conjugated $\mathrm{C}-\mathrm{H}$-acidic quinone 1c occur, which lead to a complex mixture of products. In contrast, the reaction of the same nitrile imine 7d with the structurally analogous 1,4-quinone 1d, bearing the
OMe group at $\mathrm{C}(2)$, provided the known pyrazole 9d as the only product in the excellent yield of $96 \%$ after typical aqueous work-up, although the reaction required a longer reaction time (3 d, Scheme 4). Presumably, the initially formed [3 + 2]-cycloadduct 10b undergoes spontaneous elimination of $\mathrm{MeOH}$, yielding the aromatized product 9d. A similar mechanistic scenario was observed and discussed previously for the reactions of trifluoroacetonitrile imines 7 with enol ethers used as dipolarophiles [27].

An additional experiment deserves a brief comment. The $[3+2]$-cycloaddition of $\mathbf{7 d}(\mathrm{X}=\mathrm{Me})$, generated from $\mathbf{8 d}$, with 2,3,5,6-tetramethyl-1,4-benzoquinone (1e), performed under the optimized conditions ( $2 \mathrm{~d}$ at $\mathrm{rt}$ ), yielded the fairly stable nonaromatic [3+2]-cycloadduct 10c, which was isolated by chromatographic work-up in 53\% yield (Scheme 5).

The presence of $\approx 40 \%$ of unconsumed quinone $1 \mathrm{e}$ in the crude reaction mixture evidenced that the observed fully chemoselec-

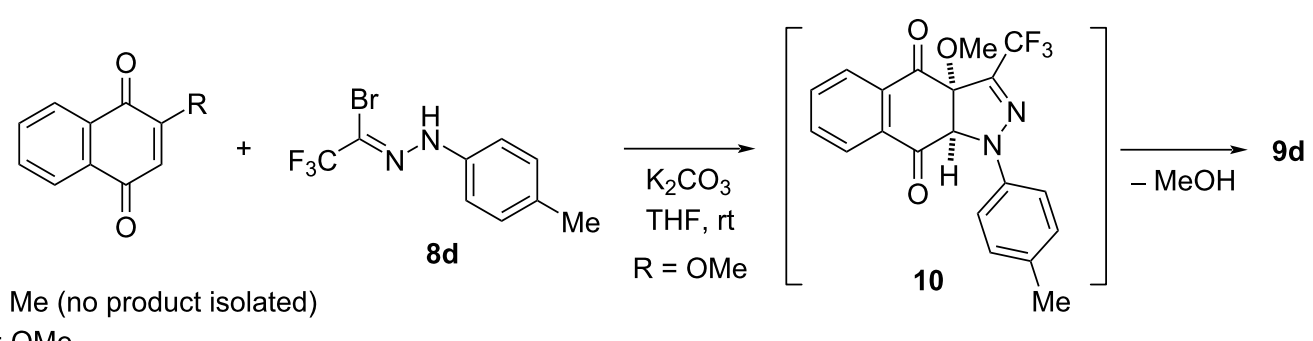

1c, $R=$ Me (no product isolated)

1d, $\mathrm{R}=\mathrm{OMe}$ 
<smiles>CC1=C(C)C(=O)C(C)=C(C)C1=O</smiles>

$1 e$<smiles>Cc1ccc(NN=C(Br)C(F)(F)F)cc1</smiles>

8d<smiles>CC1=C(C)[C@]2(C)C(C(F)(F)F)=NN([AlH2])[C@]2(C)C1=O</smiles>

$10 \mathrm{c}(53 \%)$

Scheme 5: Formation of the thermally stable, initially formed [3+2]-cycloadduct $10 \mathrm{c}$ obtained from $1 \mathrm{e}$ and nitrile imine $\mathbf{7 d}$ generated from $8 \mathrm{~d}$.

tive cycloaddition reaction with the sterically congested $\mathrm{C}=\mathrm{C}$ bond in 1e occurs less efficiently than in 2,3-unsubstituted 1,4quinones, such as 1a and $\mathbf{1 b}$. However, in that case, the subsequent elimination step leading to an aromatized product cannot take place.

All products of the type $\mathbf{9}$ are colored, typically pale yellow, both in the solid state and in solution. The UV-vis spectroscopic analysis of the naphthoquinone-derived series (compounds $\mathbf{9 a}-\mathbf{h})$ revealed less intense absorption in the visible range at $\approx 410 \mathrm{~nm}$ and medium-intensity absorption between $310-340 \mathrm{~nm}$. In the latter region, a significant hypsochromic shift of the maxima with increasing electron-withdrawing character of the substituent X could be observed (Figure 3).

Remarkably, the 1,4-anthraquinone-derived products $9 \mathbf{i}, \mathbf{9 k}$, and 9l exhibit two overlapping absorption bands in the visible range with maxima at $\lambda_{\max } \approx 400 \mathrm{~nm}$ and $\approx 425 \mathrm{~nm}$, respectively.

\section{Conclusion}

The presented study demonstrated that 1,4-quinones undergo efficient $[3+2]$-cycloadditions with in-situ-generated electrondeficient trifluoroacetonitrile imines to give polycyclic pyrazole derivatives as exclusive products formed via spontaneous air oxidation of the initial $[3+2]$-cycloadducts. In contrast to some arylnitrile oxides and benzonitrile ylides, no competitive cycloaddition to the $\mathrm{C}=\mathrm{O}$ bonds of the quinone molecule has been observed, and all studied reactions proceeded chemoselectively with the $\mathrm{C}=\mathrm{C}$ bond as the only dipolarophilic center. This result corresponds to other reported cases in which nonfluorinated nitrile imines were employed to form fused pyrazoles in reactions with 1,4-quinones. Interestingly, reactions of paraquinone methides with common nitrile imines proceeded with different chemoselectivity, and in these cases, the exocyclic $\mathrm{C}=\mathrm{C}$ bond played the role of the exclusive dipolarophilic center, yielding corresponding spiropyrazoles $[39,40]$.

This unusual selectivity in [3+2]-cycloadditions of less electron-deficient nitrile imines was studied computationally to rationalize the observed pathways [41]. Hence, it is worth mentioning that the fused pyrazoles, which are attractive compounds for diverse practical applications in medicinal and materials chemistry, are available not only by the aza-Nenitzescu reaction $[42,43]$ but also via simple and highly efficient $[3+2]$-cycloadditions of nitrile imines with the $\mathrm{C}=\mathrm{C}$ bond of 1,4-quinones. In general, the present study emphasizes the great importance of nitrile imines as versatile 1,3-dipoles useful for the preparation of $\mathrm{N}$-heterocycles of potential importance for
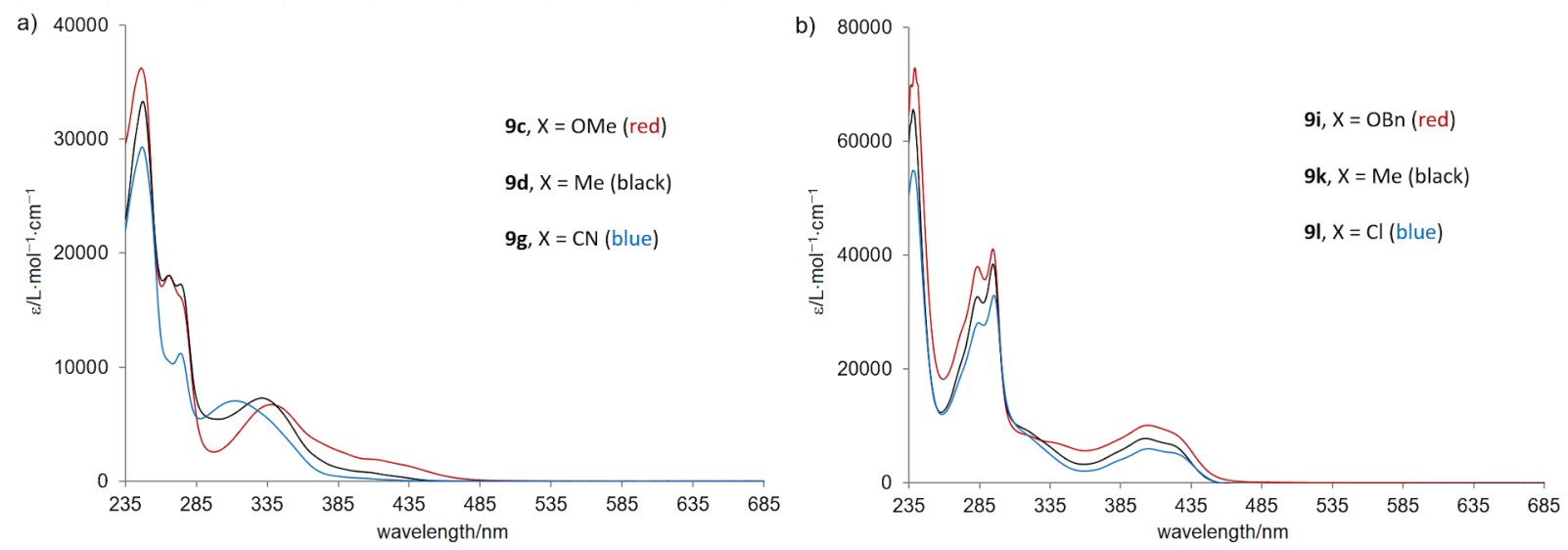

Figure 3: Electronic absorption spectra for selected a) naphthoquinone-derived (9c, 9d, 9g) and b) anthraquinone-derived (9i, 9k, 9l) trifluoromethylated pyrazoles in $\mathrm{CH}_{2} \mathrm{Cl}_{2}$. 
medicinal chemistry, agrochemistry, and materials chemistry $[44,45]$.

\section{Experimental \\ General information}

If not stated otherwise, reactions were carried out under inert atmosphere (argon) in flame-dried flasks with addition of the reactants by using syringes; subsequent manipulations were conducted in air. Products were purified by standard column chromatography (CC) on silica gel (230-400 mesh; deactivated prior to use with $2 \% \mathrm{Et}_{3} \mathrm{~N}$ in petroleum ether) by using freshly distilled solvents as eluents (petroleum ether, $\mathrm{CH}_{2} \mathrm{Cl}_{2}$, AcOEt) or recrystallized from hot $\mathrm{CHCl}_{3}$. THF was dried over sodium and benzophenone and freshly distilled before use; anhydrous DMF was purchased and used as received. The NMR spectra were measured on a Bruker AVIII instrument $\left({ }^{1} \mathrm{H}\right.$ at $600 \mathrm{MHz}$, ${ }^{13} \mathrm{C}$ at $151 \mathrm{MHz}$, and ${ }^{19} \mathrm{~F}$ at $565 \mathrm{MHz}$ ). Chemical shifts are reported relative to residual undeuterated solvent peaks (for $\mathrm{CDCl}_{3}:{ }^{1} \mathrm{H}$ NMR $\delta=7.26 \mathrm{ppm},{ }^{13} \mathrm{C} \mathrm{NMR} \delta=77.0 \mathrm{ppm}$; for 1,1,2,2-tetrachloroethane- $d_{2}\left(\mathrm{C}_{2} \mathrm{D}_{2} \mathrm{Cl}_{4}\right):{ }^{1} \mathrm{H}$ NMR $\delta=6.0 \mathrm{ppm}$, $\left.{ }^{13} \mathrm{C} \mathrm{NMR} \delta=73.8 \mathrm{ppm}\right)$ or to $\mathrm{CFCl}_{3}\left({ }^{19} \mathrm{~F} \mathrm{NMR} \delta=0.00 \mathrm{ppm}\right)$ used as external standard. Multiplicities of the signals in ${ }^{13} \mathrm{C}$ NMR spectra were assigned based on supplementary 2D measurements (COSY, HMQC, and HMBC). The UV-vis spectra were measured on a PerkinElmer Lambda 45 spectrophotometer in spectroscopic grade $\mathrm{CH}_{2} \mathrm{Cl}_{2}$. MS (ESI) were performed with a Varian 500-MS LC Ion Trap. The IR spectra were measured neat with an Agilent Cary 630 FTIR spectrometer. Elemental analyses were obtained with a Vario EL III instrument (Elementar Analysensysteme GmbH). Melting points were determined in capillaries with a MEL-TEMP apparatus (Aldrich) or with a polarizing optical microscope (OptaTech) and are uncorrected.

\section{Starting materials}

The requisite hydrazonoyl bromides $\mathbf{8 a}-\mathbf{h}$ were prepared by NBS-mediated bromination of the corresponding trifluoroacetaldehyde hydrazones in dry DMF at room temperature as described in an earlier publication [21]. The latter arylhydrazones were obtained according to a general literature protocol by condensation of aqueous fluoral hydrate $\left(\approx 75 \%\right.$ in $\left.\mathrm{H}_{2} \mathrm{O}\right)$ with commercially available hydrazines in a closed ampoule at $75^{\circ} \mathrm{C}$ in methanol in the presence of molecular sieves (4 A) [46].

\section{General procedure}

To a stirred solution of the respective 1,4-quinone 1 (1.0 mmol) and $\mathrm{K}_{2} \mathrm{CO}_{3}$ in dry THF $(10 \mathrm{~mL})$, a hydrazonoyl bromide 8 $(1.1 \mathrm{mmol})$ was added, and stirring was continued at room temperature until the starting material 1 was fully consumed (based on TLC monitoring, petroleum ether/dichloromethane 1:1) After the resulting precipitate and unconsumed carbonate were filtered off, the solvent was removed under reduced pressure. The crude mixtures were purified by $\mathrm{CC}$ using silica gel as the stationary phase and either petroleum ether (or hexanes)/ dichloromethane or petroleum ether/AcOEt mixtures as eluent to give analytically pure products $\mathbf{9 a}-\mathbf{h}$ and $\mathbf{1 0 c}$.

\section{1-Phenyl-3-(trifluoromethyl)-1H-benzo[f]indazole- \\ 4,9-dione (9a)}

Reaction time $2 \mathrm{~d}$; $\mathrm{CC}\left(\mathrm{SiO}_{2}\right.$, petroleum ether/ $\left.\mathrm{CH}_{2} \mathrm{Cl}_{2} 2: 1\right)$; $320 \mathrm{mg}$ (93\%); yellow solid; mp $196-197{ }^{\circ} \mathrm{C}$; ${ }^{1} \mathrm{H}$ NMR $\left(\mathrm{CDCl}_{3}, 600 \mathrm{MHz}\right) \delta$ 7.56-7.62 (m, 5H, Ph), 7.79, 7.84 (2 t, $J=$ $7.5 \mathrm{~Hz}, 1 \mathrm{H}$ each, $\left.\mathrm{C}_{6} \mathrm{H}_{4}\right), 8.17,8.30(2 \mathrm{~d}, J=7.7 \mathrm{~Hz}, 1 \mathrm{H}$ each, $\left.\mathrm{C}_{6} \mathrm{H}_{4}\right) ;{ }^{13} \mathrm{C} \mathrm{NMR}\left(\mathrm{CDCl}_{3}, 151 \mathrm{MHz}\right) \delta 119.9\left(\mathrm{q},{ }^{1} J_{\mathrm{C}, \mathrm{F}}=\right.$ $\left.270.4 \mathrm{~Hz}, \mathrm{CF}_{3}\right), 120.8(i-\mathrm{C}), 125.7(2 \mathrm{CH}), 127.3,127.5(\mathrm{CH}$ each), $129.0(2 \mathrm{CH}), 130.3(\mathrm{CH}), 132.9,133.4(2 i-\mathrm{C}), 134.2$, 135.0 (CH each), 138.1, $139.0(2 i-\mathrm{C}), 140.8\left(\mathrm{q},{ }^{2} J_{\mathrm{C}, \mathrm{F}}=40.8 \mathrm{~Hz}\right.$, $\mathrm{C}(3)), 174.5,177.3(2 \mathrm{C}=\mathrm{O}) ;{ }^{19} \mathrm{~F}$ NMR $\left(\mathrm{CDCl}_{3}, 565 \mathrm{MHz}\right) \delta$ -62.82 ppm; UV-vis $\left(\mathrm{CH}_{2} \mathrm{Cl}_{2}\right) \lambda_{\max }(\log \varepsilon) 247$ (4.45), 266 (4.24), 275 (4.25), 340 (3.72), 409 (2.61), $496 \mathrm{~nm}$ (1.70); IR (neat) $v_{\max }: 3082,1677(\mathrm{C}=\mathrm{O}), 1588,1521,1495,1331,1279$, 1230, 1133, 1100, 921, $716 \mathrm{~cm}^{-1}$; ESIMS (m/z): $365.1(100$, $\left.[\mathrm{M}+\mathrm{Na}]^{+}\right), 343.1\left(12,[\mathrm{M}+\mathrm{H}]^{+}\right)$; Anal. calcd for $\mathrm{C}_{18} \mathrm{H}_{9} \mathrm{~F}_{3} \mathrm{~N}_{2} \mathrm{O}_{2}$ : C, 63.16; $\mathrm{H}, 2.65$; N, 8.18; found: $\mathrm{C}, 63.34 ; \mathrm{H}$, $2.63 ; \mathrm{N}, 8.24$ (all values are given as percentages).

\section{3a,5,6,7a-Tetramethyl-1-(p-tolyl)-3-(trifluoromethyl)-} 3a,7a-dihydro- $1 \mathrm{H}$-indazole-4,7-dione (10c)

Reaction time $2 \mathrm{~d}$; $\mathrm{CC}\left(\mathrm{SiO}_{2}\right.$, petroleum ether/AcOEt 20:1); $193 \mathrm{mg}(53 \%)$; yellow oil; ${ }^{1} \mathrm{H} \mathrm{NMR}\left(\mathrm{CDCl}_{3}, 600 \mathrm{MHz}\right) \delta 1.39$ (s, 3H, Me), $1.52\left(\mathrm{q}_{\mathrm{br}}, J=0.5 \mathrm{~Hz}, 3 \mathrm{H}, \mathrm{Me}\right), 2.05-2.07(\mathrm{~m}, 6 \mathrm{H}$, $2 \mathrm{Me}$ ), 2.32 (s, 3H, Me), 6.95-6.97, 7.10-7.12 (2 m, 2H each, Tol); ${ }^{13} \mathrm{C} \mathrm{NMR}\left(\mathrm{CDCl}_{3}, 151 \mathrm{MHz}\right) \delta 13.6,13.9,14.2,14.6$, $20.8(5 \mathrm{Me}), 64.8,80.1(2 i-\mathrm{C}), 120.7\left(\mathrm{q},{ }^{1} J_{\mathrm{C}, \mathrm{F}}=271.1 \mathrm{~Hz}, \mathrm{CF}_{3}\right)$, 120.7, 129.6 (2CH each), $134.8(i-\mathrm{C}), 140.0\left(\mathrm{q},{ }^{2} J_{\mathrm{C}, \mathrm{F}}=36.3 \mathrm{~Hz}\right.$, $\mathrm{C}(3)), 139.5,146.9,147.1$ (3i-C), 192.6, 195.1 (2C=O) ppm; ${ }^{19} \mathrm{~F}$ NMR $\left(\mathrm{CDCl}_{3}, 565 \mathrm{MHz}\right) \delta-61.45 \mathrm{ppm}$; IR (neat) $v_{\max }$ : 2930, 1677 (C=O), 1513, 1506, 1379, 1267, 1170, 1118, 1070, 1029, 954, 850, 816, $712 \mathrm{~cm}^{-1}$; ESIMS $(\mathrm{m} / \mathrm{z}): 365.4$ (100, $[\mathrm{M}+\mathrm{H}]^{+}$); Anal. calcd for $\mathrm{C}_{19} \mathrm{H}_{19} \mathrm{~F}_{3} \mathrm{~N}_{2} \mathrm{O}_{2}: \mathrm{C}, 62.63$; $\mathrm{H}, 5.26$; $\mathrm{N}, 7.69$; found: C, 62.76; H, 5.39; N, 7.95.

\section{Supporting Information}

\section{Supporting Information File 1}

General information and experimental data of all isolated products, details of the crystal structure determination, and copies of ${ }^{1} \mathrm{H}$ and ${ }^{13} \mathrm{C}$ NMR spectra for all products. [https://www.beilstein-journals.org/bjoc/content/ supplementary/1860-5397-17-108-S1.pdf] 


\section{Funding}

Financial support by the University of Lodz in the framework of the IDUB program (M. J., grant no. 3/IDUB/DOS/2021) and a Student Research Grant (K. N.) are gratefully acknowledged.

\section{ORCID ${ }^{\circledR}$ iDs}

Greta Utecht-Jarzyńska - https://orcid.org/0000-0003-4444-7544 Karolina Nagła - https://orcid.org/0000-0002-9678-1504 Grzegorz Mlostoń - https://orcid.org/0000-0003-3631-3239 Heinz Heimgartner - https://orcid.org/0000-0002-5145-4251 Marcin Palusiak - https://orcid.org/0000-0002-0032-0878 Marcin Jasiński - https://orcid.org/0000-0002-8789-9690

\section{References}

1. El-Najjar, N.; Gali-Muhtasib, H.; Ketola, R. A.; Vuorela, P.; Urtti, A.; Vuorela, H. Phytochem. Rev. 2011, 10, 353-370. doi:10.1007/s11101-011-9209-1

2. Wang, Y.; Zhu, S.; Zou, L.-H. Eur. J. Org. Chem. 2019, 2179-2201. doi:10.1002/ejoc.201900028

3. Han, C.; Li, H.; Shi, R.; Zhang, T.; Tong, J.; Li, J.; Li, B. J. Mater. Chem. A 2019, 7, 23378-23415. doi:10.1039/c9ta05252f

4. Patel, O. P. S.; Beteck, R. M.; Legoabe, L. J. Eur. J. Med. Chem. 2021, 210, 113084. doi:10.1016/j.ejmech.2020.113084

5. Nawrat, C. C.; Moody, C. J. Angew. Chem., Int. Ed. 2014, 53 , 2056-2077. doi:10.1002/anie.201305908 Angew. Chem. 2014, 126, 2086-2109. doi:10.1002/ange.201305908

6. Tapia, R. A.; Carrasco, C.; Ojeda, S.; Salas, C.; Valderrama, J. A.; Morello, A.; Repetto, Y. J. Heterocycl. Chem. 2002, 39, 1093-1096. doi:10.1002/jhet.5570390540

7. Wang, C.; Chen, X.-H.; Zhou, S.-M.; Gong, L.-Z. Chem. Commun. 2010, 46, 1275-1277. doi:10.1039/b917246g

8. Berhe, S.; Slupe, A.; Luster, C.; Charlier, H. A., Jr.; Warner, D. L.; Zalkow, L. H.; Burgess, E. M.; Enwerem, N. M.; Bakare, O. Bioorg. Med. Chem. 2010, 18, 134-141. doi:10.1016/j.bmc.2009.11.011

9. Huang, H.-M.; Gao, J.-R.; Ye, Q.; Yu, W.-B.; Sheng, W.-J.; Li, Y.-J. RSC Adv. 2014, 4, 15526-15533. doi:10.1039/c4ra01593b

10. Morrocchi, S.; Quilico, A.; Ricca, A.; Selva, A. Gazz. Chim. Ital. 1968, 98, 891-906.

11. Shiraishi, S.; Holla, B. S.; Imamura, K. Bull. Chem. Soc. Jpn. 1983, 56, 3457-3463. doi:10.1246/bcsj.56.3457

12. Hamadi, N. B.; Msaddek, M. Heterocycl. Commun. 2006, 12, 457-462. doi:10.1515/hc.2006.12.6.457

13. Shiraishi, S.; Ikeuchi, S.; Senō, M.; Asahara, T. Bull. Chem. Soc. Jpn. 1977, 50, 910-913. doi:10.1246/bcsj.50.910

14. Shiraishi, S.; Ikeuchi, S.; Senō, M.; Asahara, T. Bull. Chem. Soc. Jpn. 1978, 51, 921-925. doi:10.1246/bcsj.51.921

15. Stegmann, W.; Uebelhart, P.; Heimgartner, H. Helv. Chim. Acta 1983, 66, 2252-2268. doi:10.1002/hlca.19830660736

16. Gilgen, P.; Jackson, B.; Hansen, H.-J.; Heimgartner, H.; Schmid, H. Helv. Chim. Acta 1974, 57, 2634-2643. doi:10.1002/hlca.19740570842

17. Huisgen, R.; Seidel, M.; Wallbillich, G.; Knupfer, H. Tetrahedron 1962, 17, 3-29. doi:10.1016/s0040-4020(01)99001-5

18. Argyropoulos, N. G.; Mentzafos, D.; Terzis, A. J. Heterocycl. Chem. 1990, 27, 1983-1988. doi:10.1002/jhet.5570270725
19. Ortiz-Rojano, L.; Rojas-Martín, J.; Rodríguez-Diaz, C.; Carreño, M. C.; Ribagorda, M. Chem. - Eur. J. 2019, 25, 15050-15054. doi:10.1002/chem.201904138

20. Bertuzzi, G.; Crotti, S.; Calandro, P.; Bonini, B. F.; Monaco, I.; Locatelli, E.; Fochi, M.; Zani, P.; Strocchi, E.; Mazzanti, A.; Chiariello, M.; Franchini, M. C. ChemMedChem 2018, 13, 1744-1750. doi:10.1002/cmdc.201800251

21. Mlostoń, G.; Urbaniak, K.; Utecht, G.; Lentz, D.; Jasiński, M.

J. Fluorine Chem. 2016, 192, 147-154 doi:10.1016/j.jfluchem.2016.10.018

22. Utecht, G.; Sioma, J.; Jasiński, M.; Mlostoń, G. J. Fluorine Chem. 2017, 201, 68-75. doi:10.1016/j.jfluchem.2017.07.014

23. Grzelak, P.; Utecht, G.; Jasiński, M.; Mlostoń, G. Synthesis 2017, 49, 2129-2137. doi:10.1055/s-0036-1588774

24. Utecht-Jarzyńska, G.; Jasiński, M.; Świątek, K.; Mlostoń, G.; Heimgartner, H. Heterocycles 2020, 101, 251-262. doi:10.3987/com-19-s(f)20

25. Utecht-Jarzyńska, G.; Mykhaylychenko, S. S.; Rusanov, E. B.; Shermolovich, Y. G.; Jasiński, M.; Mlostoń, G. J. Fluorine Chem. 2021, 242, 109702. doi:10.1016/j.jluchem.2020.109702

26. Utecht-Jarzyńska, G.; Michalak, A.; Banaś, J.; Mlostoń, G.; Jasiński, M. J. Fluorine Chem. 2019, 222-223, 8-14. doi:10.1016/j.jfluchem.2019.04.012

27. Utecht, G.; Fruziński, A.; Jasiński, M. Org. Biomol. Chem. 2018, 16, 1252-1257. doi:10.1039/c7ob03126b

28. Utecht, G.; Mlostoń, G.; Jasiński, M. Synlett 2018, 29, 1753-1758. doi:10.1055/s-0037-1610454

29. Tian, Y.-C.; Li, J.-K.; Zhang, F.-G.; Ma, J.-A. Adv. Synth. Catal. 2021, 363, 2093-2097. doi:10.1002/adsc.202100091

30. Kowalczyk, A.; Utecht-Jarzyńska, G.; Mlostoń, G.; Jasiński, M. J. Fluorine Chem. 2021, 241, 109691. doi:10.1016/j.jfluchem.2020.109691

31. Fustero, S.; Sánchez-Roselló, M.; Barrio, P.; Simón-Fuentes, A. Chem. Rev. 2011, 111, 6984-7034. doi:10.1021/cr2000459

32. Kaur, K.; Kumar, V.; Gupta, G. K. J. Fluorine Chem. 2015, 178 , 306-326. doi:10.1016/j.jfluchem.2015.08.015

33. Zhou, Y.; Wang, J.; Gu, Z.; Wang, S.; Zhu, W.; Aceña, J. L.; Soloshonok, V. A.; Izawa, K.; Liu, H. Chem. Rev. 2016, 116, 422-518. doi:10.1021/acs.chemrev.5b00392

34. Hu, X.-G.; Hunter, L. Beilstein J. Org. Chem. 2013, 9, 2696-2708. doi:10.3762/bjoc.9.306

35. Mykhailiuk, P. K. Chem. Rev. 2021, 121, 1670-1715. doi:10.1021/acs.chemrev.0c01015

36. Lipunova, G. N.; Nosova, E. V.; Charushin, V. N.; Chupakhin, O. N. J. Fluorine Chem. 2015, 175, 84-109. doi:10.1016/j.jluchem.2015.03.011

37. Mlostoń, G.; Urbaniak, K.; Urbaniak, P.; Marko, A.; Linden, A.; Heimgartner, H. Beilstein J. Org. Chem. 2018, 14, 1834-1839. doi:10.3762/bjoc.14.156

38. Mlostoń, G.; Celeda, M.; Heimgartner, H. Heterocycles 2003, 59 , 767-777. doi:10.3987/com-02-s61

39. Woolhouse, A. D. Aust. J. Chem. 1977, 30, 1145-1152. doi:10.1071/ch9771145

40. Su, Y.; Zhao, Y.; Chang, B.; Zhao, X.; Zhang, R.; Liu, X.; Huang, D.; Wang, K.-H.; Huo, C.; Hu, Y. J. Org. Chem. 2019, 84, 6719-6728. doi:10.1021/acs.joc.9b00434

41. Soleymani, M.; Jahanparvar, S. Monatsh. Chem. 2020, 151, 51-61. doi:10.1007/s00706-019-02531-2 
42. Lyubchanskaya, V. M.; Alekseeva, L. M.; Granik, V. G. Chem. Heterocycl. Compd. 1999, 35, 570-574.

doi:10.1007/bf02324640

43. Janardhanan, J. C.; Mishra, R. K.; Das, G.; Sini, S.; Jayamurthy, P.; Suresh, C. H.; Praveen, V. K.; Manoj, N.; Babu, B. P.

Asian J. Org. Chem. 2018, 7, 2094-2104. doi:10.1002/ajoc.201800413

44. Quadrelli, P., Ed. Modern Applications of Cycloaddition Chemistry; Elsevier: Amsterdam, Netherlands, 2019.

doi:10.1016/c2017-0-03259-7

45. Jamieson, C.; Livingstone, K., Eds. The Nitrile Imine 1,3-Dipoles Properties, Reactivity and Applications; Springer: Cham, Switzerland, 2020. doi:10.1007/978-3-030-43481-6

46. Wojciechowska, A.; Jasiński, M.; Kaszyński, P. Tetrahedron 2015, 71, 2349-2356. doi:10.1016/j.tet.2015.03.015

\section{License and Terms}

This is an Open Access article under the terms of the Creative Commons Attribution License

(https://creativecommons.org/licenses/by/4.0). Please note that the reuse, redistribution and reproduction in particular requires that the author(s) and source are credited and that individual graphics may be subject to special legal provisions.

The license is subject to the Beilstein Journal of Organic Chemistry terms and conditions:

(https://www.beilstein-journals.org/bjoc/terms)

The definitive version of this article is the electronic one which can be found at: https://doi.org/10.3762/bjoc. 17.108 